\title{
Differential response rates of two concurrently available instrumental drinking responses'
}

HENRY L. TAYLOR ${ }^{2}$ AND ROBERT W. SCHAEFFER

FLORIDA STATE UNIVERSITY
A technique which permits a paired comparison examination of instrumental licking preferences is described. Saccharin preference for two female rats was demonstrated by comparing differential instrumental lick rates on concurrently available saccharin and water in a lick-to-run contingency.

Preference can be defined as differential responding in the presence of concurrently available stimuli. The rat's preference for sweet solutions over water when both are freely available, and when water and various concentrations of sweet solutions are contingent upon an instrumental bar-pressing response is well established (Young, 1955).

Although fluid ingestion has typically been used as a reinforcing response, Premack (1963) and Schaeffer (1965) have shown that drinking may be used as an instrumental response. These experiments used only one instrumental drinking response, but the procedure is of interest since it provides a new technique for examining response preferences.

The purpose of the present experimenter was to use a drink-to-run contingency to examine differential rates of responding on concurrently available saccharin and water drinking responses, either of which would satisfy the experimenter-imposed contingency of drink-to-run. Method

The Ss were two 150-day-old female Sprague-Dawley rats. The Ss were maintained on ad lib Purina Lab Chow. Ad lib water was available except during the $6-\mathrm{hr}$. period immediately preceding each test session.

The apparatus was a standard York Engineering Company activity wheel-twin drinkometer test chamber. This apparatus provides for the measurement of operant level running and drinking, and for the arrangement of contingencies between running and drinking and has been described in detail elsewhere (Premack et al, 1964). Each 1/4 wheel turn and each lick were recorded on counters and a digital recorder. White noise was used to mask background sounds.

The Ss were first given seven, $1 / 2 \mathrm{hr}$, adaptation sessions in which they were permitted to run and to drink from both water-loaded tubes. Thereafter two daily sessions, each $10 \mathrm{~min}$. in duration, were conducted for all of the contingency test sessions.

Following adaptation, the opportunity to run was made contingent upon licking the water tubes; an FR of 5 licks on either water tube freed the wheel for a 10 sec. contingent time (CT 10). These test sessions were continued until running, licking, and trials stabilized. (For all contingent sessions, a trial was defined by completion of the FR 5 and freeing of the wheel, and a successful running response (SRR) was defined as four $1 / 4$ wheel turns during a trial.) Asymptote was considered attained for each $S$ when the submeans of responding for the first and the last six of 12 consecutive sessions differed from the grand mean of the 12 sessions by less than $10 \%$. Running was exceptionally stable for both Ss during these test sessions; the submeans of running differed from the grand mean of running by $5 \%$ for S A, and by less than $1 \%$ for S B. Neither S showed a systematic tube position preference, and both Ss showed SRR's for greater than $98 \%$ of the trials.
After the drink-water-to-run contingency reached asymptote, the preference test was initiated. In the preference sessions the contingency (FR 5, CT 10) was retained, but one tube contained .1\% saccharin solution and the other tube contained water. The position of the saccharin tube was alternated over sessions in a RLLR sequence. The preference testing sessions were continued until running, saccharin licks, and the saccharin preference score (S-score equals rates of saccharin licks to total licks multiplied by 100) reached asymptote. The criterion for asymptote was the same as that described above.

\section{Resulis}

Differential responding on the water and saccharin tubes in the pre-asymptotic and in the asymptotic sessions is shown in Fig. 1. As is evident from this figure, a definite preference for saccharin was found for both Ss. The principle difference between the two Ss was the lower S-scores for SA during the pre-stability sessions; the low S-score for $\mathrm{S} A$ was 74 during these sessions, compared with a low S-score of 94 for S B. The mean S-score for SA and SB in the asymptotic sessions, however, was 95 and 98 respectively, with no significant difference within or between Ss.

Asymptotic running and saccharin licking were highly stable. The variability between the submeans and the grand mean for running was $4 \%$ for $\mathrm{SA}$, and less than $1 \%$

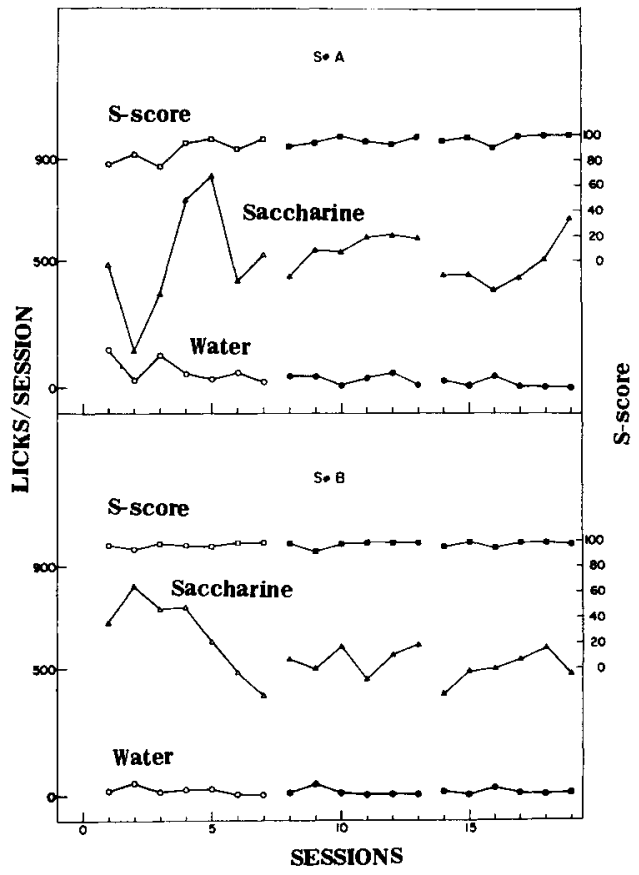

Fig. 1. Differential instrumental lick responding on concurrently available water and saccharin solutions in the first seven sessions (open symbols) and asymptotic sessions (solid symbols) of drinkto-run contingency preference test. 

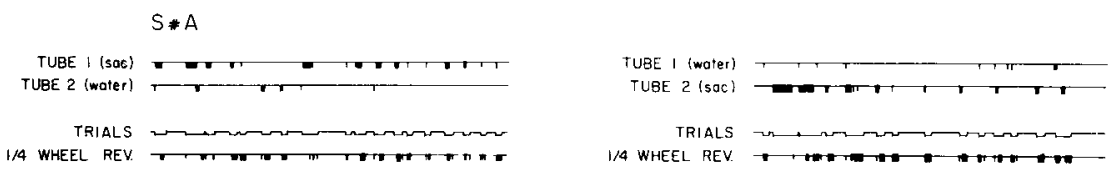

14 WHEEL REV + T.
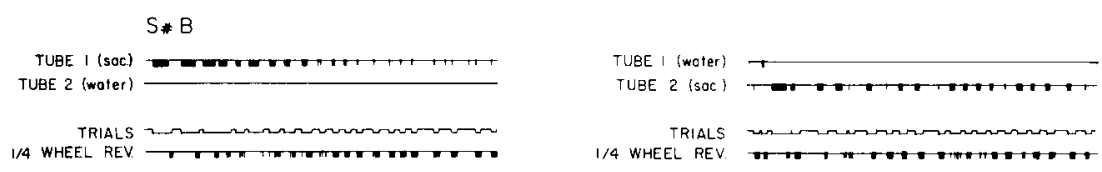

Fig. 2. Representative records for $S \mathbf{A}$ and $S$ B showing saccharin and water licks, trials (wheel free), and $1 / 4$ wheel revolutions. The down ward deflections indicate responses and wheel availability. All records read from left to right.

for S B. Asymptotic saccharin licking showed variations of $7 \%$ and $4 \%$ for S A and S B, respectively.

Representative Esterline-Angus records for both Ss which show differential responding when saccharin was contained in tube 1, and in tube 2, are presented in Fig. 2. These records illustrate the finding that no position responding independent of tube content was obtained, and indicate that the variable controlling the $\mathrm{Ss}^{7}$ tube selection was tube content. As is also illustrated in Fig. 2 , if an initial response was made to water, both Ss typically switched to saccharin prior to completion of the FR. S B seldom shifted tubes once it had located the saccharin; S A, however, consistently sampled both drinking tubes throughout each session.

Further examination of the Esterline-Angus records indicated that more overshooting of the FR 5 occurred during the first $5 \mathrm{~min}$. of each session than during the last $5 \mathrm{~min}$. of each session. The effectiveness of the contingency, however, was illustrated by the fact that S A and S B completed SRR's on $94.5 \%$ and $95.5 \%$ of the trials, respectively.

\section{Discussion}

The differential instrumental lick response rates obtained from the concurrently available water and saccharin solution showed that saccharin was consistently preferred over water, thus confirming the well established preference rats have for sweet solutions over water in the free choice method and in the contingent case where the test solution is the reinforcing event (Young, 1955).

Wagner et al (1965) reviewed the methodology used in preference tests, found that the results varied as a function of the methods used ${ }_{8}$ and suggested that the most appropriate method for unbiased determination of preference is the free choice paired comparison method. The technique used in the present study is essentially a free choice paired comparison method, with the added advantage of permitting preference assessment as a function of parameters other than the quality of the proffered solutions per se. For example, the present technique permits preference assessment as a function of (1) rate of the contingent response, and (2) "cost" of preferred response, as defined by the schedule requirements imposed on the instrumental drinking responses.

The present results also bear directly on the reported failure of individual Ss to conform precisely to contingency schedule requirements (Schaeffer, 1966). Schaeffer reported that Ss with high precontingency instrumental response rates (i.e., established response preferences) overshoot $\mathrm{FR}$ requirements more than do Ss with low precontingency instrumental response rates. Although FR overshooting decreased within sessions in the present study, presumably as a function of satiation effects, both Ss exceeded the FR 5 lick requirement, more markedly for the preferred saccharin response than for water.

\section{References}

Premack, D. Prediction of the comparative reinforcement values of running and drinking. Science, 1963, 139, 1062-1063.

Premack, D., Schaeffer, R. W., \& Hundt, A. Reinforcement of drinking by running: Effect of fixed ratio and reinforcement time. J. exp. Anal. Behav., 1964, 91-96.

Schaeffer, $\mathbf{R}$. W. The reinforcement relation as a function of in strumental response rate. J. exp. Psychol., 1965, 69, 419-425.

Schaeffer, R. W. Overshooting of the FR requirement. Psychol. Rec., 1966, 16, 17-23.

Wagner, M. W., Green, K. F., \& Manley, M. B. Paired comparison method for measurement of sugar preference in squirrel monkeys. Science, $1965,148,1473-1474$.

Young, P. T. The role of hedonic processes in motivation. In Marshall R. Jones (Ed.), Nebraska Symposium on Motivation. Lincoln: Univ. of Nebraska Press, 1955.

\section{Notes}

1. Supported by PHS Grant MH 08775, from the National Institute of Mental Health.

2. Now at 6571st Aeromedical Research Laboratory, Holloman AFB, New Mexico. 